\title{
Editorial: Autism - Hype and Hope
}

\author{
Sheffali Gulati $^{1}$ - Saima Hossain ${ }^{2} \cdot$ Jane Squires $^{3}$
}

Received: 9 November 2016 / Accepted: 10 November 2016 / Published online: 22 November 2016

(C) Dr. K C Chaudhuri Foundation 2016

Autism spectrum disorder (ASD) is a common neurodevelopmental disorder that affects nearly $1 \%$ of children. Different data across the world have pegged the prevalence to vary from 1 in 64 (CDC) to 1 in 89 (INCLEN). This implies that pediatricians and physicians are highly likely to deal with these children in their day-to-day practice.

The first description of autism dates back to 1943, when Leo Kanner, a child psychiatrist at Johns Hopkins, wrote a seminal article, describing for the first time 11 children without social instincts to orient towards other people, and who had a "need for sameness" or a "resistance to (unexpected) change" [1]. Kanner named this new psychiatric condition "infantile autism". A year later, pediatrician Hans Asperger, at the University of Vienna in Austria, described a group of children in his clinic who shared many of the same features [2]. Asperger's article was written in German and went unnoticed until 1981, when Lorna Wing, brought it to the attention of the autism community [3]. Asperger described a wide gamut of features of his patients across a wide age range, with different social and emotional characteristics. These diverse features described more than half a century ago form the "autism spectrum".

Sheffali Gulati

sheffaligulati@gmail.com

1 Child Neurology Division, Department of Pediatrics, All India Institute of Medical Sciences, New Delhi 110029, India

2 WHO's Expert Advisory Panel on Mental Health, National Advisory Committee on Autism, Shuchona Foundation, Dhaka, Bangladesh

3 Early Intervention/Special Education, Early Intervention Program, University Center for Excellence in Developmental Disabilities, University of Oregon, Eugene, OR, USA
Since these early descriptions, the diagnosis of autism has evolved from autism to autism spectrum disorder, and this evolution continues as we read this special edition. The current DSM-5 criteria form the basis of diagnosis of autism, with numerous tools available that can facilitate the diagnosis [4]. Some of the tools have been converted into a mobile-based application to promote point of care application.

The management of autism involves behavioral interventions including applied behavioral analysis (ABA) and developmental strategies to enable social communication and reduce challenging behaviors. ABA involves teaching new skills repetitively, in a controlled and responsive environment, until successfully acquired. This is commonly referred to as discrete trial training, and should be implemented in accordance with a child's developmental level, within the child's natural environment, if possible. The child's interests with toys or activities should also be considered, guided by a teacher or parent, who may then use strategies like modeling, verbal and/or hand over hand prompting to teach social and communication skills. Social and communication interventions are predominantly taught in the course of a child's neurodevelopmental maturation. Hence it is imperative that autism is diagnosed early in the course of childhood after application of appropriate screening and diagnostic tests.

In this issue, we have attempted to capture the aforementioned aspects of autism, including its diagnostic evolution over the past six to seven decades, along with current diagnostic standards as proposed by Mintz [5]. Mintz also writes about important clinical aspects including the central nervous system, gastro-intestinal issues and sleep disruptions.

Lowering the age of identification of young children with autism spectrum disorder (ASD) is of critical importance. Research studies have confirmed the benefits of early and intensive intervention for young children with autism. In this 
issue, Nickel and Huang-Storms discuss screening and surveillance batteries for early identification of ASD [6]. They describe various screening tests including CHAT, M-CHAT, ITC, and GARS, along with their psychometric properties such as sensitivity and specificity. Sengupta and colleagues deliberate the educational and behavioral interventions for management of ASD [7]. Their article presents challenges and solutions tailored to the Indian context.

Impairments in social communication skills are a core feature of ASD. Watkins et al. have elucidated evidence-based practices for improving communication among children with ASD [8], including developmentally-appropriate strategies. In addition, Barua et al. provide an overview of currently available government approaches and rights of children with ASD in society [9].

Our endeavor was to provide current evidence based recommendations on major aspects of ASD. Of course we have missed many issues in this broad field, including neurotherapeutics, biomarkers development, functional MRI, and virtual reality techniques. Since the final word on these new technologies is yet to come, we have instead incorporated well-established diagnostic approaches and intervention models.

This special issue of the Indian Journal of Pediatrics includes detailed accounts on many critical topics related to ASD. Our main goal is to educate the pediatricians and physicians so that children with autism are identified early on, using accurate screening and diagnostic evaluations, that they receive effective interventions, and are integrated into the mainstream, without stigma or limitations.

\section{Compliance with Ethical Standards}

Conflict of Interest None.

Source of Funding None.

\section{References}

1. Kanner L. Autistic disturbances of affective contact. Nervous Child. 1943;2:217-50.

2. Asperger H. Die autistischen psychopathen im Kindesalter. Arch fur Psychiatrie und Nerven Krankheiten. 1944;117:76-136.

3. Wing L. Asperger's syndrome: a clinical account. Psychol Med. 1981;11:115-29.

4. American Psychiatric Association. Diagnostic and statistical manual of mental disorders. 5th ed. Arlington, VA: American Psychiatric Publishing; 2013.

5. Mintz M. Evolution in the understanding of autism spectrum disorder: historical perspective. Indian J Pediatr. 2016; doi:10.1007/s12098016-2080-8.

6. Nickel RE, Huang-Storms L. Early identification of young children with autism spectrum disorder. Indian J Pediatr. 2015; doi:10.1007/s12098-015-1894-0.

7. Sengupta K, Lobo L, Krishnamurthy V. Educational and behavioral interventions in management of autism spectrum disorder. Indian $\mathrm{J}$ Pediatr. 2015; doi:10.1007/s12098-015-1967-0.

8. Watkins L, Kuhn M, Ledbetter-Cho K, Gevarter C, O'Reilly M. Evidence-based social communication interventions for children with autism spectrum disorder. Indian J Pediatr. 2015; doi:10.1007/s12098-015-1938-5.

9. Barua M, Kaushik JS, Gulati S. Legal provisions, educational services and health care across the lifespan for autism spectrum disorders in India. Indian J Pediatr. 2016; doi:10.1007 /s12098-016-2261-5. 